\title{
Gust Encounter Simulations of a Generic Transport Aircraft and Analysis of Load Alleviation Potentials by Control Surface Deflections Using a RANS-CFD-based Multidisciplinary Simulation Environment
}

\author{
Andreas-René Hübner \\ German Aerospace Center (DLR), Institute of Aerodynamics and Flow Technology \\ Lilienthalplatz 7, 38108 Braunschweig, Germany \\ Email: Andreas.Huebner@dlr.de \\ Lars Reimer \\ German Aerospace Center (DLR), Institute of Aerodynamics and Flow Technology \\ Lilienthalplatz 7, 38108 Braunschweig, Germany \\ Email: Lars.Reimer@dlr.de
}

\begin{abstract}
The structural dimensioning of an aircraft is decisively influenced by gust, maneuver and ground loads. Adaptive load alleviation promises the potential of reducing maximum loads and hence structural weight. For appropriate analysis of the effectiveness of load alleviation technologies, a multidisciplinary approach is imperative. Against this backdrop, a multidisciplinary process chain for gust encounter simulation in the time domain is applied using high fidelity methods for the main disciplines involved: aerodynamics, structural dynamics and flight mechanics. In the sense of a sensitivity study, the influences of gust amplitude, gust wavelength and direction on integral loads and component loads of a generic transport aircraft in cruise flight are investigated. Encounters with single gusts and series of gusts are considered. The potentials of load reductions by aileron deflections are studied.
\end{abstract}

\section{Nomenclature}

\begin{tabular}{|c|c|c|c|c|c|}
\hline Ampl & Gust amplitude & $\mathrm{m} / \mathrm{s}$ & $\mathrm{Ma}$ & Mach-Number & - \\
\hline Accz & Acceleration in $\mathrm{z}$-direction & $\mathrm{m} / \mathrm{s}^{2}$ & $\operatorname{Re}$ & Reynolds-Number & - \\
\hline Accy & Acceleration in $y$-direction & $\mathrm{m} / \mathrm{s}^{2}$ & $\mathrm{Fz}$ & Force component in z-direction & $\mathrm{N}$ \\
\hline $\mathrm{CL}$ & Lift coefficient & - & $\mathrm{t}$ & Time & $\mathrm{s}$ \\
\hline $\mathrm{CY}$ & Side force coefficient & - & $\mathrm{t}$ & Thrust setting & - \\
\hline $\mathrm{Cmx}$ & Roll moment coefficient & - & LRA & Load Reference Axis & - \\
\hline Cmy & Pitch moment coefficient & - & $\mathrm{RBE}$ & Rigid Body Element & - \\
\hline $\mathrm{Cmz}$ & Yaw moment coefficient & - & $\alpha$ & Angle of attack & $\operatorname{deg}$ \\
\hline CFD & Computational Fluid Dynamic & & $\rho$ & Density & $\mathrm{kg} / \mathrm{m}^{3}$ \\
\hline CFM & Computational Fluid Mechanic & - & $\lambda$ & Wavelength of the gust & $\mathrm{m}$ \\
\hline CONM & Concentrated Mass Element & - & $\eta_{\text {НTP }}$ & $\begin{array}{l}\text { Trim angle at horizontal tail } \\
\text { plane }\end{array}$ & $\operatorname{deg}$ \\
\hline CSM & Computational Structure Mechanic & - & $\eta$ & Aileron deflection angle & $\operatorname{deg}$ \\
\hline CS-25 & $\begin{array}{l}\text { Certification Specifications for } \\
\text { Large Aeroplanes }\end{array}$ & - & $\Theta$ & Angle of pitch & $\operatorname{deg}$ \\
\hline FD & Flight Dynamic & - & $6 \mathrm{DOF}$ & 6 Degree of Freedom & - \\
\hline FL & Flight Level & & & & \\
\hline
\end{tabular}




\section{Introduction}

T oad analysis plays a key role in aircraft design: it provides the sizing load cases for designing the aircraft's Lstructural layout [1]. Adaptive load alleviation shows promise to reduce maximum loads and structural weight. For the accurate prediction of aerodynamic loads, monodisciplinary approaches are insufficient. The impact on loads of the aircraft's structural dynamics and flight mechanics reaction during gust encounters and maneuvers must be taken into account properly. The multidisciplinary loads analysis procedures currently in place in industry rely on low fidelity aerodynamics though (usually potential theory methods), lacking the ability to render important loadsaffecting flow features (e.g. shocks, flow separation, ...). Here, an analysis approach is thus pursued that is based on URANS-based CFD solvers. A process chain was established in which a state-of-the-art RANS CFD solver featuring advanced turbulence modeling is coupled in the time domain to individual solvers for the structural dynamics problem (CSD) and rigid-body dynamics problem (6DOF). The process chain is used for accurate analysis of gust loads. The use case is a generic transport aircraft in cruise flight and for transonic flight condition. It is investigated in sensitivity studies how gust amplitude, gust wavelength and direction affect integral loads and component loads. Encounters with single gusts and series of gusts are considered. First steps towards analyses of load reduction potentials have been taken. Gust encounter simulations with various predefined time histories of symmetrical aileron deflections are performed. The activity is part of a larger strategy towards more high-fidelitybased loads analysis and its use in the context of HiFi-MDO-driven aircraft design [2].

\section{Numerical Methods}

For the simulation of unsteady gust interaction, a multidisciplinary process chain is used, which was developed within the DLR project Digital-X [3]. In the process chain, following a partitioned approach, high fidelity methods for the disciplines aerodynamics, structural dynamics and rigid-body dynamics are coupled in the time domain. The process chain is implemented in the FlowSimulator software environment [2],[4],[5], supporting massively parallel applications.

Gust encounter simulations are performed for a generic transport aircraft in cruise flight. The loads exerted on the aircraft in clean configuration (undeflected ailerons) are studied in comparison to those with manual controlled aileron deflections.

\section{A. CFD models}

The generic transport aircraft investigated is shown in Fig. 1. For preliminary simplification, no powered engine is used yet but just a flow-through nacelle. Ailerons are modeled as movables. They can be deflected by means of mesh deformation (see detail in Fig. 1). For computations of the unsteady flow field, DLR's URANS solver TAU is applied [6] using hybrid unstructured grids generated with the mesh generator CENTAUR by CentaurSoft [7]. A coarse grid with 10 million grid points is used in function tests of the process chain and for qualitative investigations. A finer grid with 27 million grid points is used for quantitative analyses.

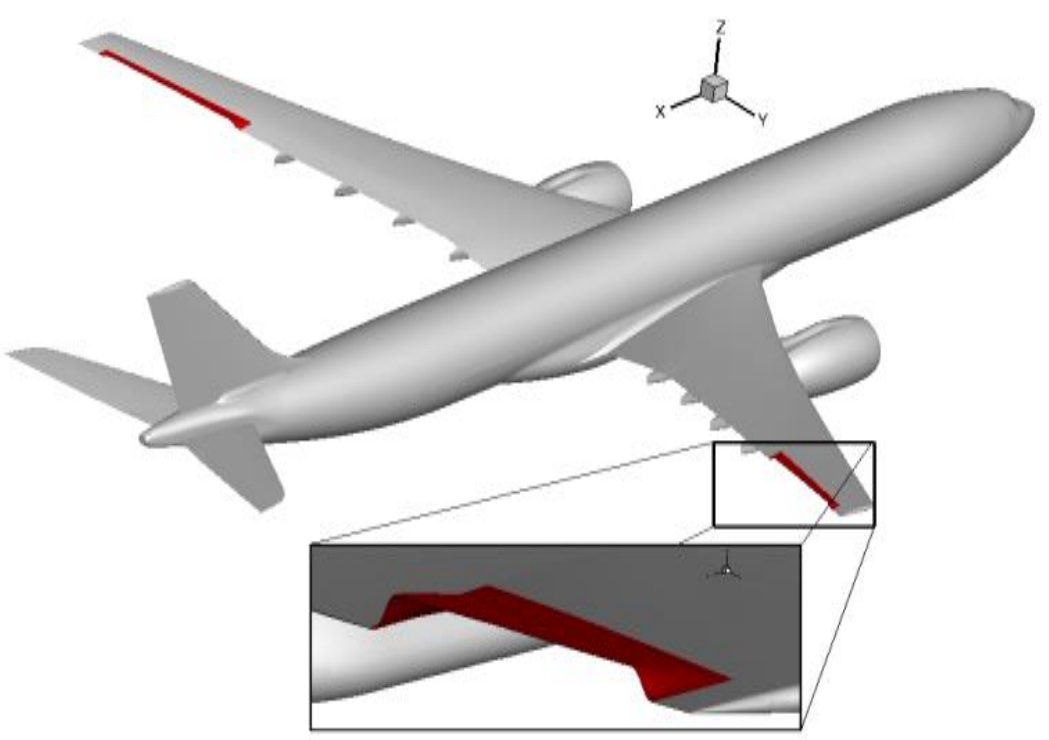

Figure 1: Surface model of the generic transport aircraft with movable ailerons (red), here deflected symmetrically upwards by 20 degrees 


\section{B. Structure and coupling model}

A FEM model condensed for dynamic analysis (a so-called Dynamic Master Model) is used. It was created by the DLR Institute of Aeroelasticity. Fig. 2 shows the A-Set nodes of the model. In their entirety, they form the socalled load reference axis (LRA). The model is designed as a "free-free" model and is therefore statically indeterminate. Inertia properties resulting from structure, secondary systems, fuel and payload distribution are modeled as concentrated mass points (NASTRAN CONM2 elements).

To solve the structural dynamics problem, a modal method is applied. The lowest 44 elastic eigenmodes of the structure are considered. They are computed in an offline step by NASTRAN SOL103 [5].

As part of the load and deformation transfer between CFD surface and structure, an extended structural model is used. Additional structural nodes (so-called coupling points) are distributed on the CFD surface and rigidly via RBE2 elements to the LRA nodes, representing the elastic structure

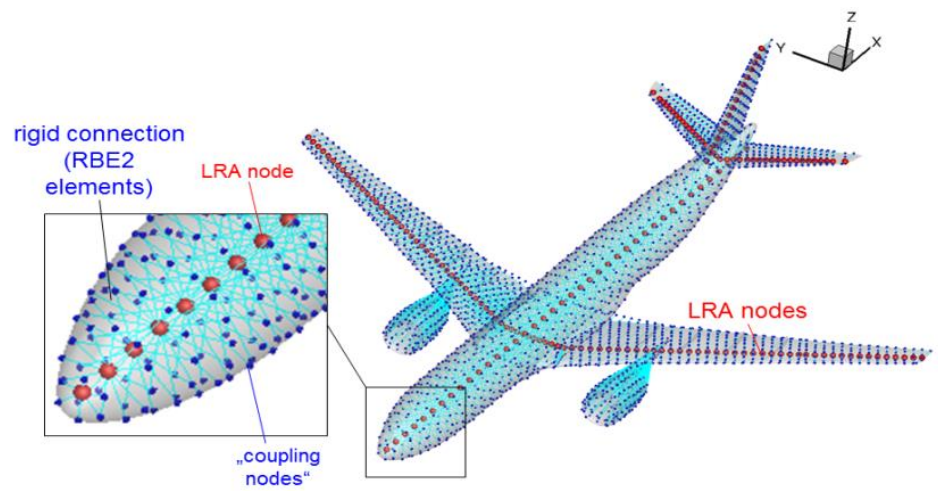

Figure 2: Structural model (including additional nodes for CFD-CSD coupling = "coupling model")

\section{Process chain}

In the multidisciplinary process chain applied, the aircraft aerodynamics is computed using DLR's URANS solver TAU [8]. It also has the capability to model the effects of gusts in various forms. If the aircraft's flight dynamics response and elastic behavior are to be taken into account, TAU is coupled with a modal method for solving the linearized rigid-body motion equations and a modal structural dynamics solver. A schematic of the multidisciplinary solver approach used is shown in Fig. 3 [9].

For load and deformation interpolation between aerodynamic surface and structure, a thin-plate spline is applied. It is generated between the points of the CFD surface mesh and the coupling points of the structural model [4]. The

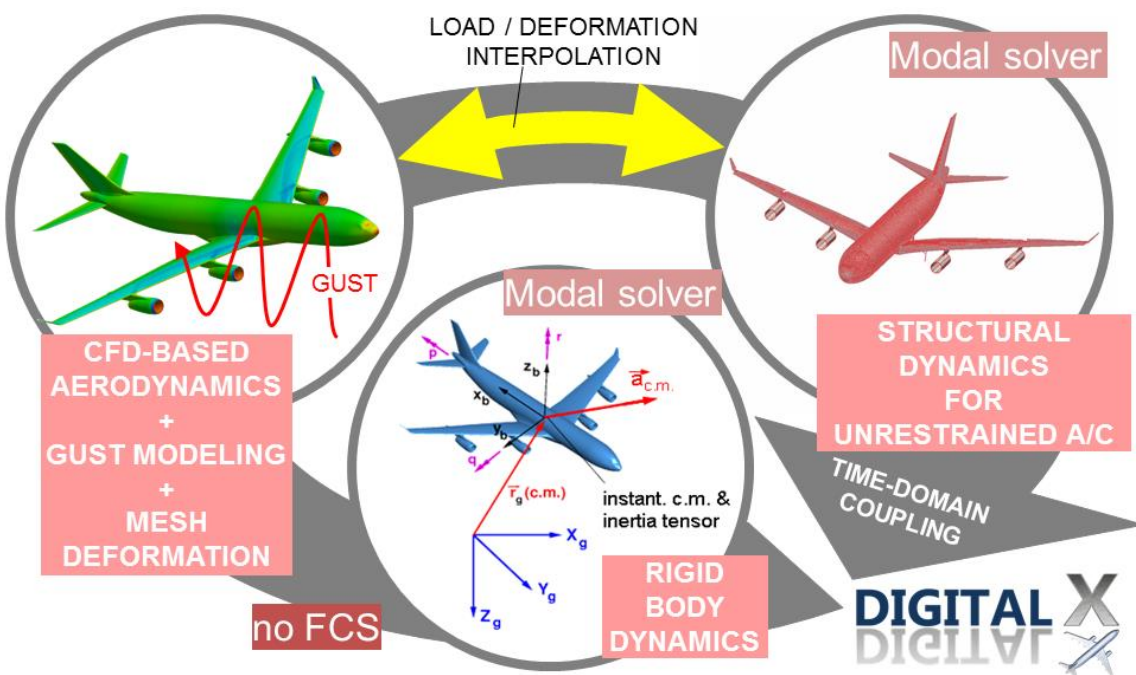

Figure 3: Schematic of the multidisciplinary solver approach applied deformation transferred to the CFD surface is propagated into the CFD volume grid using RBFbased mesh deformation (a volume spline is used).

Prior to a transient gust encounter simulation, the non-accelerated flight state of the elastic aircraft (i.e. its cruise flight shape) needs to be found for given flight conditions. A trimming algorithm based on Newton's method is used, iteratively adjusting the trim degrees of freedom---pitch angle $\theta$, horizontal tail plane setting angle $\eta_{\text {HTP }}$ and 
engine thrust setting $\mathrm{t}\left(=F_{\text {thrust }, x} / \mathrm{G}\right)$.---until overall forces and moments around the aircraft's center of gravity vanish [4], [10]. The horizontal tail plane is adjusted using mesh deformation, while imposing a sliding mesh boundary condition on the fuselage.

Fig. 4 shows the computed trimmed flight state of the aircraft at the flight condition of interest. This results in an pitch angle of $\theta=3^{\circ}$, an horizontal tail plane setting angle of $\eta_{\text {НTP }}=2,9^{\circ}$ at an engine thrust setting of $t=-0.0539$.

The flight control system (FCS) has not been integrated into the process chain yet. Feedback controlled control surface deflections so far thus cannot be taken into account. Therefore, controlled surface deflections requirements can only be used by manual specification of the time-dependent aileron deflection.

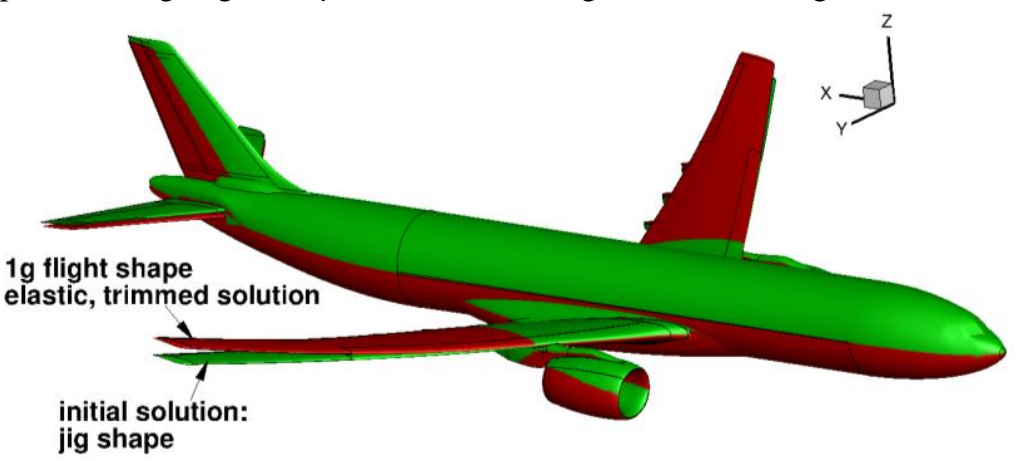

Figure 4: Flight shape of the elastic generic aircraft configuration

\section{Sensitivity studies}

In order to gain a better understanding of the coupled simulation, sensitivity studies were carried out to investigate various influencing variables of the gust simulation on the aerodynamic, elastic, flight-mechanical behavior of the aircraft configuration during a gust passage.

\section{A. General description of the gust characteristic}

A snapshot of a sample coupled CFDCSD-6DOF gust encounter simulation for the use case of this paper is shown in Fig. 5. All numerical simulations were carried out at $\mathrm{Ma}=0.83, \mathrm{Re}=49$ million and FL 350. The gust amplitude in that case is $\widehat{U}_{\text {gust }}=10 \mathrm{~m} / \mathrm{s}$; the wavelength is $\lambda=100 \mathrm{~m}$.

In gust encounter simulations, an additional velocity field - e.g. for a vertical or a lateral gust - is taken into account, which is described in more details in [11],[12]. Fig. 5 also shows a vertical disturbance velocity field, which influences the flow around the aircraft.

Fig. 6 shows the time-dependent lift and pitching moment coefficients resulting from the gust encounter simulation presented in Fig. 5. Starting point of the transient
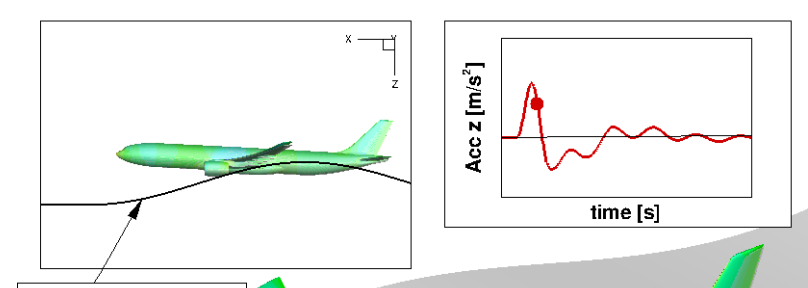
time [s]

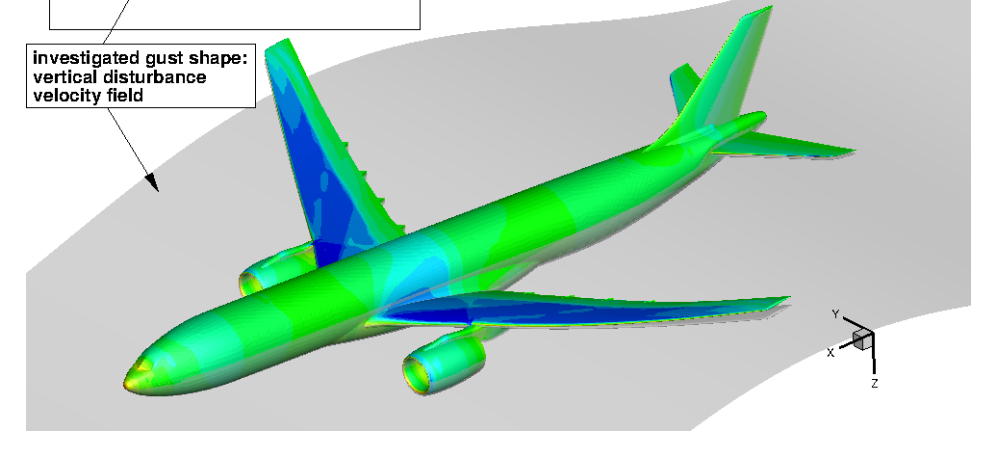

Figure 5: Example of an unsteady gust simulation simulation at $\mathrm{t}=0 \mathrm{~s}$ is the trimmed nonaccelerated flight state of the elastic aircraft. The grey area in Fig. 6 (top) marks the time range in which the gust maximum passes from the aircraft's nose $(t=0.41 \mathrm{~s})$ to its tail $(\mathrm{t}=0.77 \mathrm{~s})$. At time $\mathrm{t}=0.57 \mathrm{~s}$, the gust peak is at the moment reference point. 

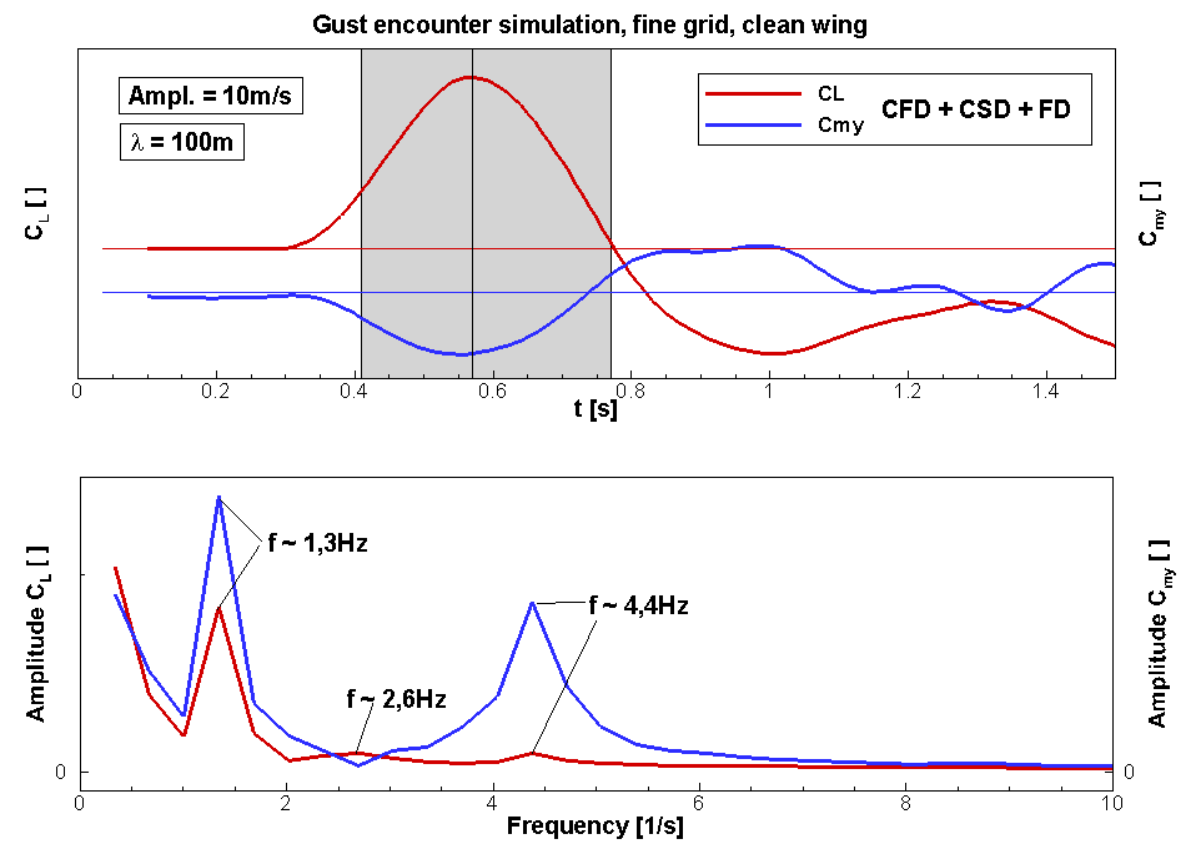

Figure 6: Figure 6: Top: Time histories of lift and pitching moment coefficients resulting from the CFD-CSD6DOF-coupled simulation of the gust encounter scenario shown in Fig. 5; Bottom: results of a power spectral density analysis

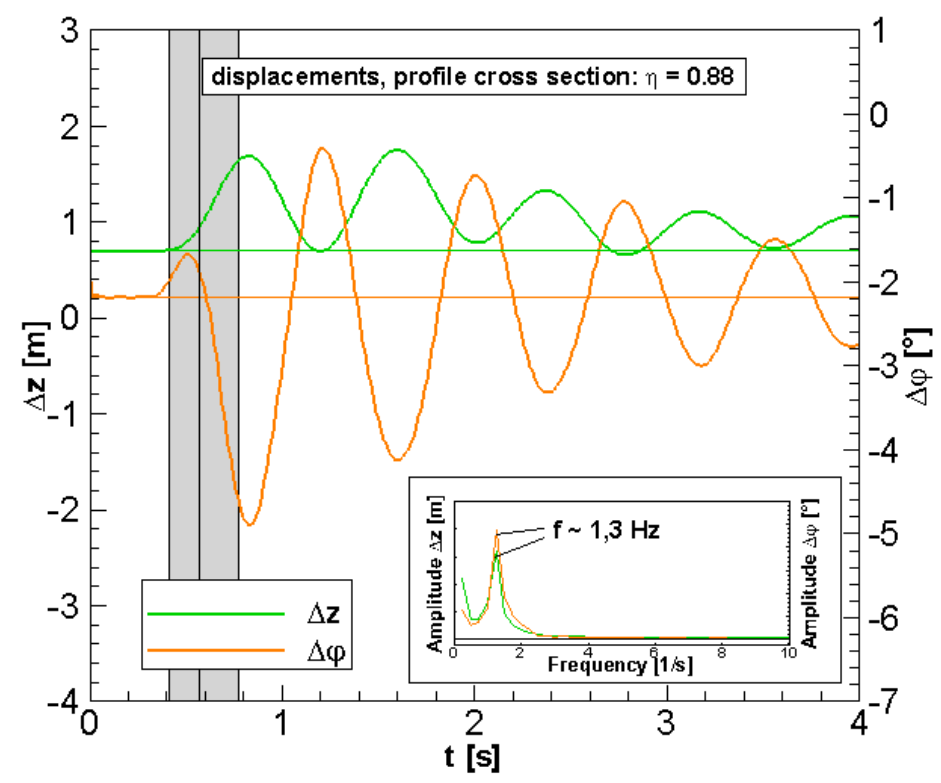

Figure 7: Bending displacement and twist of a wing airfoil section at $\eta=0.88$

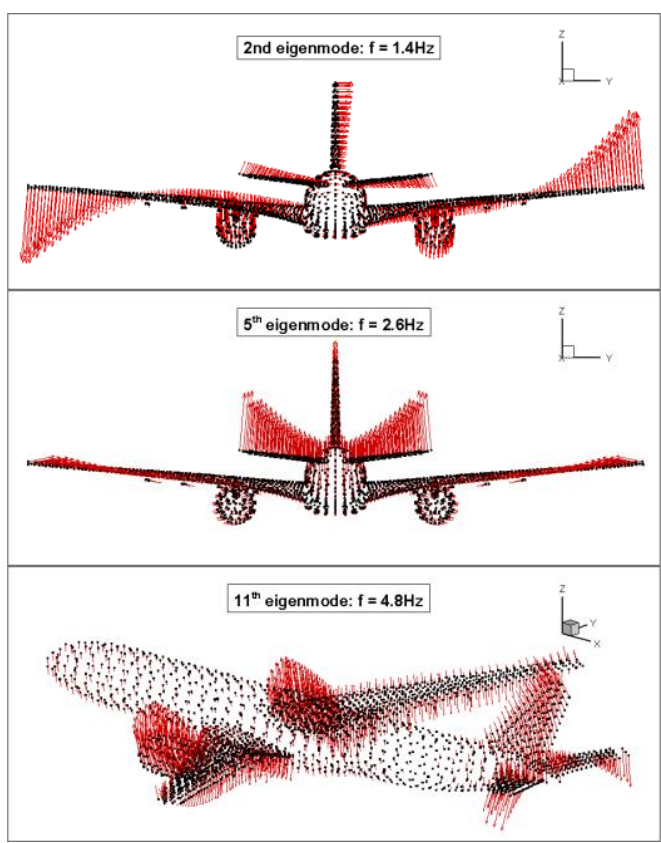

Figure 8: Structural modes at the relevant frequencies, displacement vectors at the coupling nodes 
The power spectral density (PSD) spectrum of $\mathrm{C}_{\mathrm{my}}(\mathrm{t}$ ), see Fig. 6 (bottom), shows pronounced peaks at frequencies $\mathrm{f} \sim 1.3 \mathrm{~Hz}$ and $\mathrm{f} \sim 4.6 \mathrm{~Hz}$; the first one correponding to the natural frequency of the second asymmetric bending eigenmode, see also the frequency content in the time history of the displacement and twist of an outboards wing section at $\eta=0.88$, Fig. 7 . The displacement vectors at the respective coupling nodes of the structure model (see Fig. 8 at the top) confirm the bending oscillation for this frequency. In Fig. 6 (bottom), an additional minor peak is visible in the PSD spectrum of $\mathrm{C}_{\mathrm{L}}(\mathrm{t})$ at $\mathrm{f} \sim 2.6 \mathrm{~Hz}$. Inspection of the structural eigenmodes indicates, that the peaks at $\mathrm{f} \sim 2.6 \mathrm{~Hz}$ and $\mathrm{f} \sim 4.4 \mathrm{~Hz}$ result from a bending of the horizontal tail plane and a nacelle-pylon-wing interaction, see also the structural model representations in Fig 8 (middle and bottom).

\section{B. Influence of the gust amplitude}

Fig. 9 shows the time-dependent lift coefficient of the aircraft as a result of the vertical gust amplitude from $5 \mathrm{~m} / \mathrm{s}$ to $40 \mathrm{~m} / \mathrm{s}$ at a constant wavelength $\lambda=100 \mathrm{~m}$. The maximum values increase monotonically as the amplitude increases. With increasing amplitude, the time of maximum lift (not to be confused with CLmax) is reached earlier.

The resulting maximum and minimum lift coefficients and the pitching moment coefficients are plotted as a function of gust amplitude in Fig. 10. Up to amplitudes of approx. $15 \mathrm{~m} / \mathrm{s}$ the slope of all curves is linear. For higher gust amplitudes, nonlinear effects seem to emerge; that is at least what the curves of the integral aerodynamic coefficients suggest.

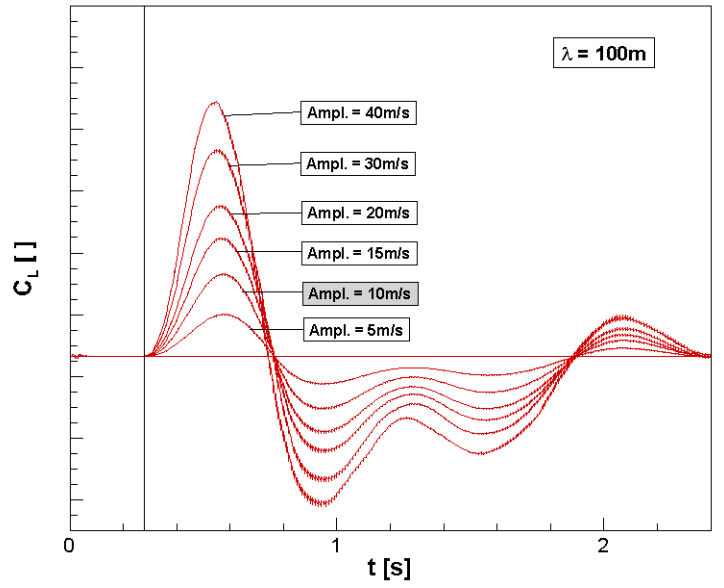

Figure 9: Influence of the gust amplitude on the lift coefficient at constant wave length $\lambda=100 \mathrm{~m}$

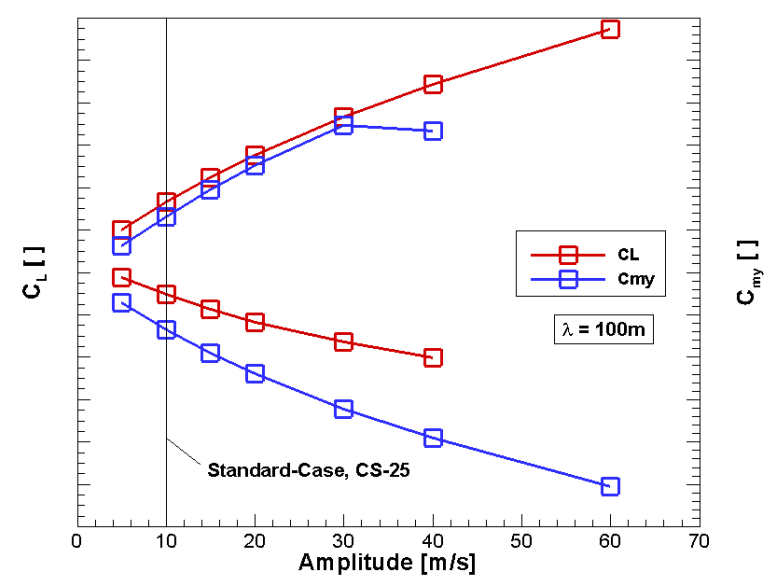

Figure 10: Influence of the gust amplitude on the minimum and maximum lift and pitching moment coefficients at constant wave length $\lambda=100 \mathrm{~m}$

\section{Influence of the wavelength}

The comparisons of the lift and pitching moment curves with variation of the wavelengths of $25 \mathrm{~m}<\lambda<200 \mathrm{~m}$ at constant gust amplitude are summarized in Fig. 11 and Fig. 12. Within the simulations the gusts of different wavelengths always start at the same $x$ position of $x=50 \mathrm{~m}$ in front of the center of gravity of the model. In this case the incipient gust influences from the fuselage nose to the fuselage tail are also shown. However, the effects are different depending on the wavelength. 


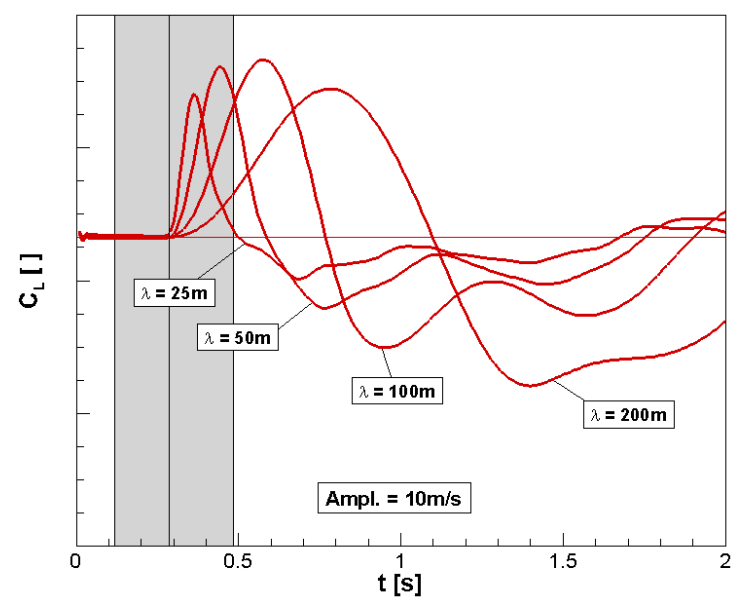

Figure 11: Influence of the gust wave length on the lift coefficient at constant amplitude $=10 \mathrm{~m} / \mathrm{s}$

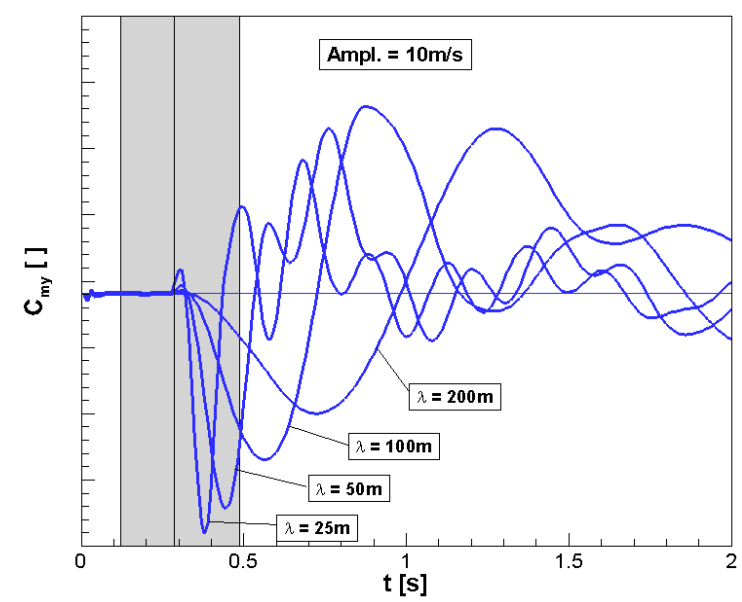

Figure 12: Influence of the gust wave length on the pitching moment coefficient at constant amplitude $=$ $10 \mathrm{~m} / \mathrm{s}$

At a wavelength of $\lambda=25 \mathrm{~m}$ the maximum vertical disturbance speed of $10 \mathrm{~m} / \mathrm{s}$ already effects the wing and the horizontal tail plane before it reaches the rear end of the fuselage. The complete effect on the tailplane plane is only given for $\lambda=50 \mathrm{~m}$ when the disturbance velocity field has already flowed further downstream. If the wavelength increases further beyond $\lambda=100 \mathrm{~m}$, the disturbance velocity field is so long that the disturbances reach the rear end of the fuselage before the wing is affected by the maximum disturbance velocity. The effects on the horizontal tail flow are still small up to this point.

If the envelope curve of the maximum lift coefficients is formed, the maximum is reached at $\lambda=100 \mathrm{~m}$. However, the maximum influence of the pitch moment is already at $\lambda=25 \mathrm{~m}$. The time histories of the pitching moment coefficient also show that when reducing the wavelength, not only the first elastic eigenmode, but also higher-harmonic oscillation components are excited, which mainly result from the eigenmodes of the wing.

Based on the load distribution of the trimmed horizontal flight condition, Fig. 13 shows the span-wise, maximum occurring force component in $\mathrm{z}$-direction $\Delta \mathrm{Fz}$ of the wing and the horizontal tail plane (htp). In the inner wing area the force components increase continuously up to $\lambda=100 \mathrm{~m}$. In the outer area, however, the wing can no longer withstand the time-dependent loads at this wavelength and deviates in this area due to the structural elasticity.

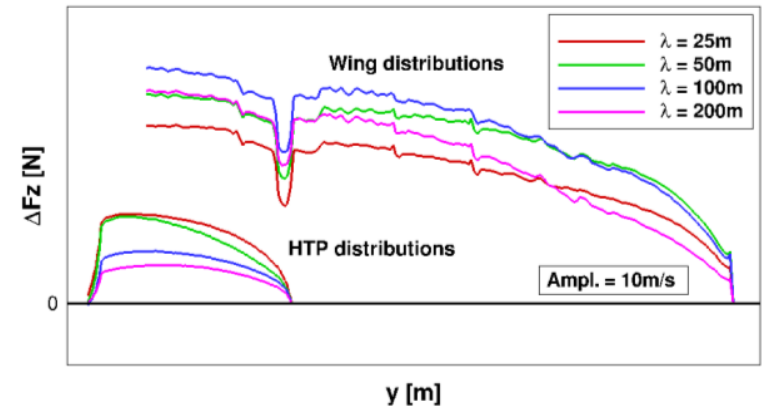

Figure 13: Influence of the gust wave length on the maximum force component $\Delta \mathrm{Fz}$ in span-wise direction of the wing and the htp

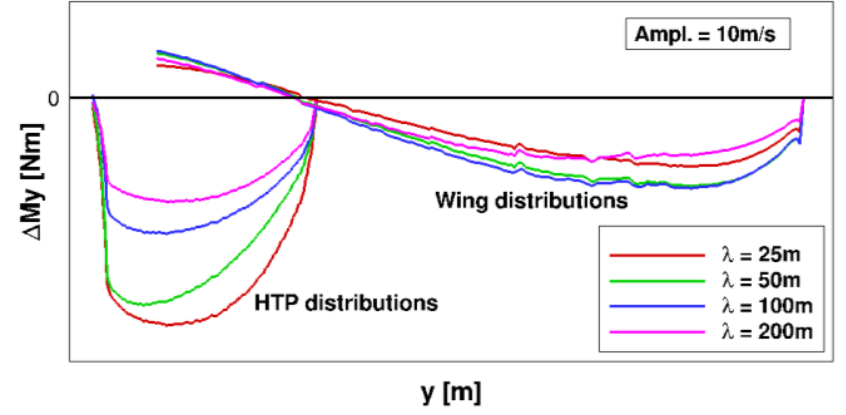

Figure 14: Influence of the gust wave length on the maximum pitching moment component $\Delta \mathrm{My}$ in span-wise direction of the wing and the htp 
This behavior is also apparent at the longest wavelength of $\lambda=200 \mathrm{~m}$, but the effects of the higher loads extend over the entire wingspan. On the other hand, with increasing wavelength, the span-wise z-force component on the horizontal tail plane increases continuously. The same wavelength dependence is also shown in the pitching moment distributions on the wing in Fig. 14. Likewise, at $\lambda=100 \mathrm{~m}$ in the outer wing area, there is a reduction of the pitching moment, which extends over the entire wingspan width at $\lambda=200 \mathrm{~m}$. The maximum decrease of the pitching moment results from the pitching moment part caused by the horizontal tail plane. For the wavelength of $\lambda=25 \mathrm{~m}$, the additional lift and thus the pitching moment component of the horizontal tail plane are qualitatively very high, so that this behavior is also reflected in the total pitching moment coefficient (see Fig. 11).

\section{Influence of gust series}

The CFD method TAU offers the possibility to simulate gust series in addition to the realization of different gust shapes. Here, up to three gusts of constant amplitudes and wavelengths from vertical and lateral directions were simulated. Fig. 15 compares the time histories of the lift coefficient from one gust to three gusts in series from the vertical direction.

The amplitudes of $10 \mathrm{~m} / \mathrm{s}$ and the wavelengths of $\lambda=100 \mathrm{~m}$ are kept constant. For the generic aircraft geometry examined here, the maximum additional lift is caused by the simulation of the first gust. The maximum lift reduction occurs with two consecutive gusts. Here the effect of the first gust in the series is lower compared to that of a single gust, but the second gust leads to an even greater lift decrease. The same behavior can be observed with three gusts in series, whereby the influence of the second gust on the total lift is lower than with the simulation of only two gusts in series.

In addition, the effects of triple gusts from vertical and lateral direction for different gust frequencies on the aerodynamic coefficients were investigated. An example is illustrated in Fig. 16.

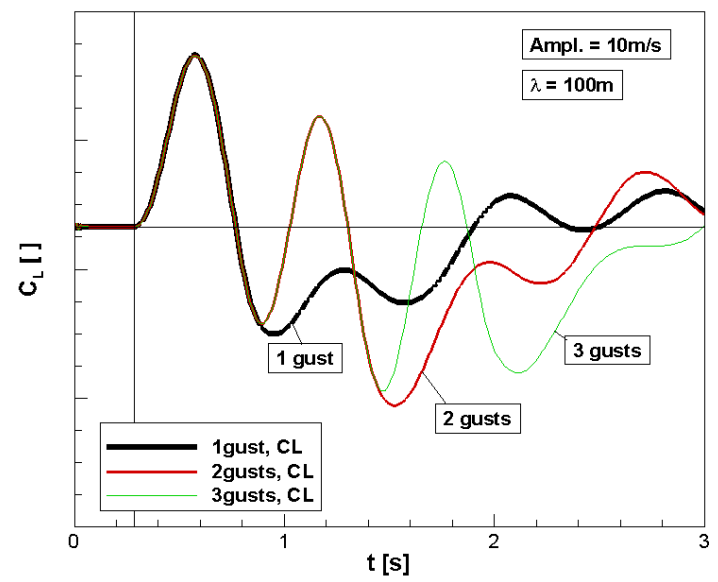

Figure 15: Influence of the number of gusts on the lift coefficient at constant amplitude and wave length

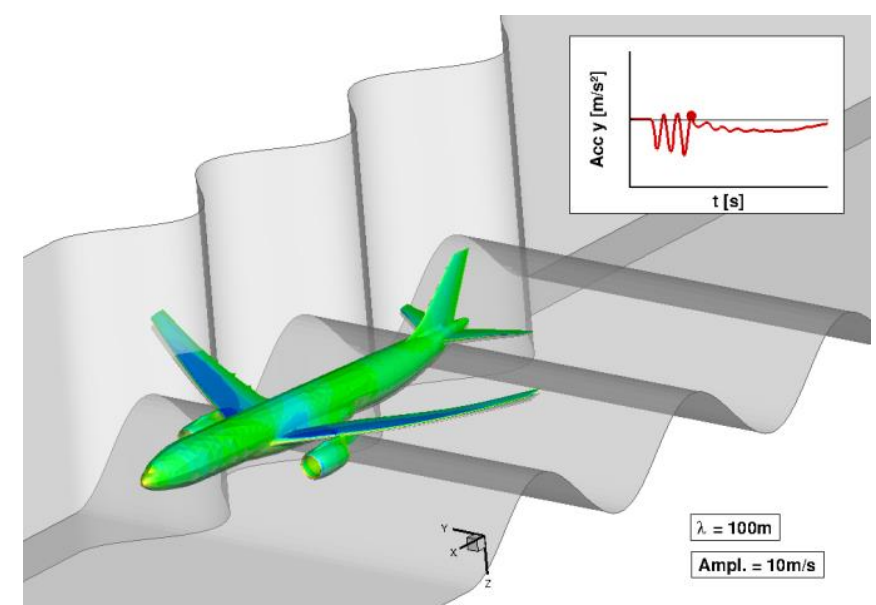

Figure 16: Example of a triple gusts simulation from vertical and lateral direction 
Fig. 17 shows the time histories of the lift coefficient with variation of the wavelength. Since the aircraft also tries to move sideways, the roll moment coefficients are also shown. At the same amplitude of $10 \mathrm{~m} / \mathrm{s}$, the wavelengths are $\lambda=30 \mathrm{~m}$ and $\lambda=100 \mathrm{~m}$. As already discussed in Fig. 10, the maximum lift increase is reached at $\lambda=100 \mathrm{~m}$. However, due to the resulting rolling moment, which results mainly from the wing geometry and its elasticities, the first gust has the greatest effect due to the higher-frequency gust excitation $(\lambda=30 \mathrm{~m})$.
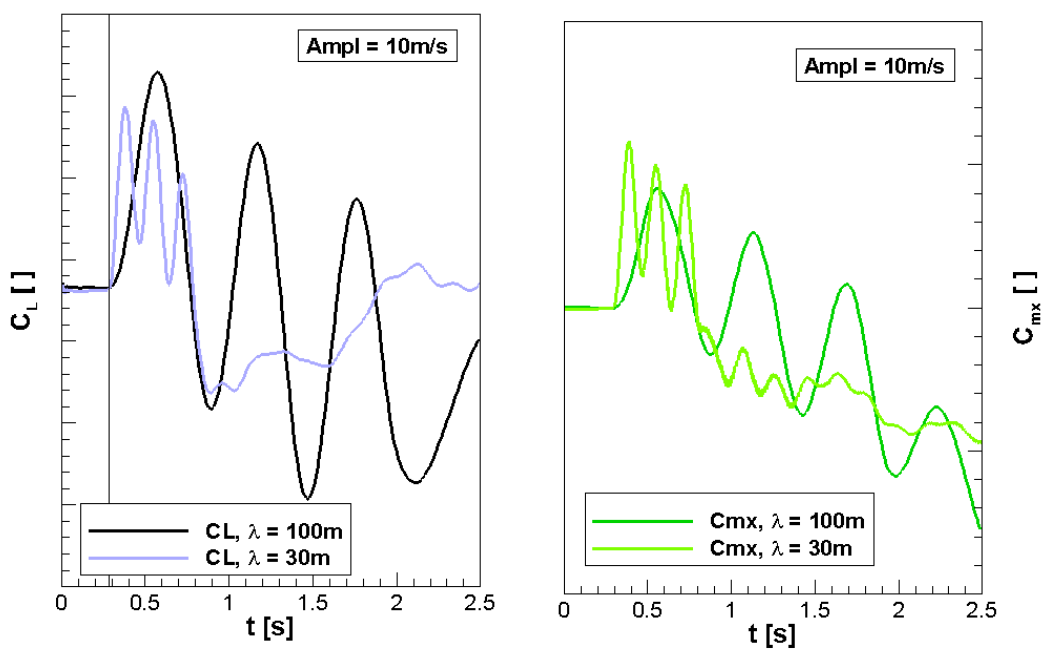

Figure 17: Influence of the number of gusts on the lift and roll moment coefficients at constant amplitude and variable wave length

The lateral gusts mainly affect the flow around the vertical tail plane, but also the fuselage. The resulting lateral force and yaw moment coefficients are shown in Fig. 18. They also show stronger effects for $\lambda=30 \mathrm{~m}$. Thus it appears that the higher-frequency gust excitation has a greater influence on the aerodynamics and therefore on the flight-mechanical behavior of this configuration.
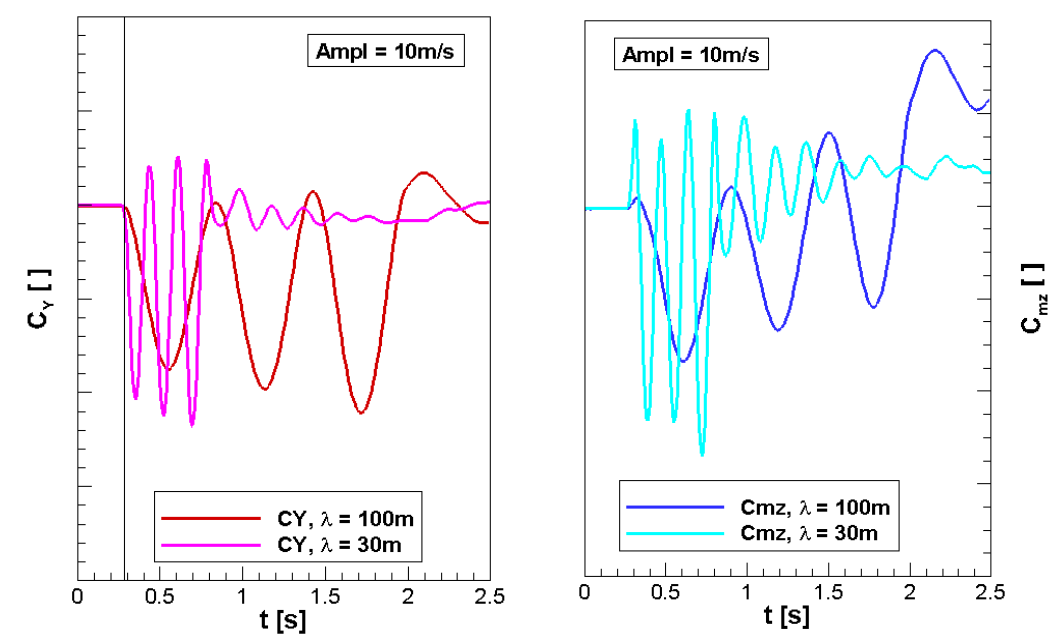

Figure 18: Influence of the number of gusts on the side force and yaw moment coefficients at constant amplitude and variable wave lengths 


\section{Influence of aileron deflections}

Three predefined time-histories of symmetrical aileron deflections shown in Fig. 19 are investigated regarding load alleviation effectiveness. These include aileron deflections using two ramp functions. The aileron can be extended either within one time step $\Delta \mathrm{t}=0.01 \mathrm{~s}$ (red) or several time steps $\Delta t=0.06 \mathrm{~s}$. In the second case, the aileron is retracted again within the same lower rotation rate (green). These are compared to a "1-cosine"-function deflected aileron (blue). In all cases, the maximum aileron deflection is -20 degrees.

Exemplarily, Fig. 20 shows the comparison of the lift and the pitching moment curves in case of gust encounter simulations of a configuration without aileron deflection to a deflected aileron of $\eta=-20^{\circ}$. The ailerons are extended at the time $t=0.5 \mathrm{~s}$ within a time step of $t=0.01 \mathrm{~s}$. Within this time step, the lift and the pitching moment behavior completely responds to the changed aileron setting.

This example shows that the aerodynamic loads can be reduced, but in this context further investigations must also be carried out to determine whether the structural properties are associated with the aerodynamic behavior.

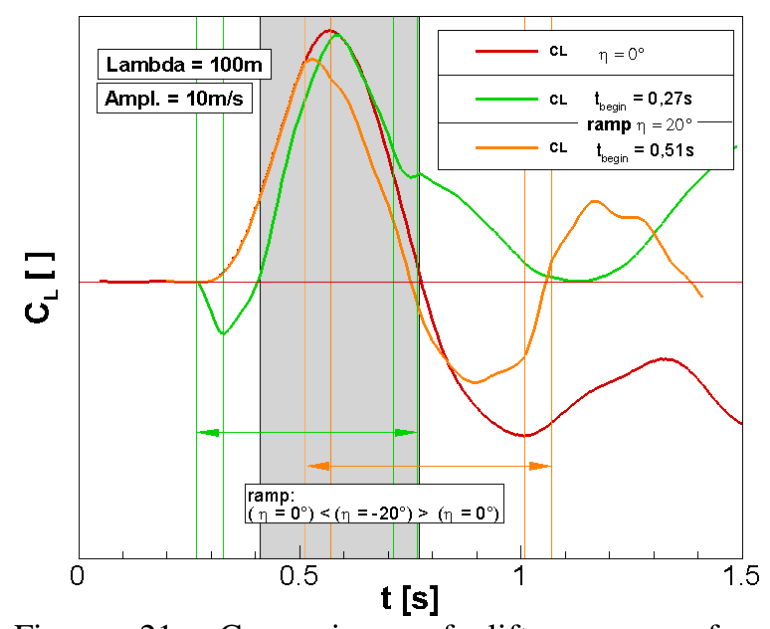

Figure 21: Comparison of lift curves of a configuration without and with aileron deflections (ramp function), variation of start time of aileron deflections

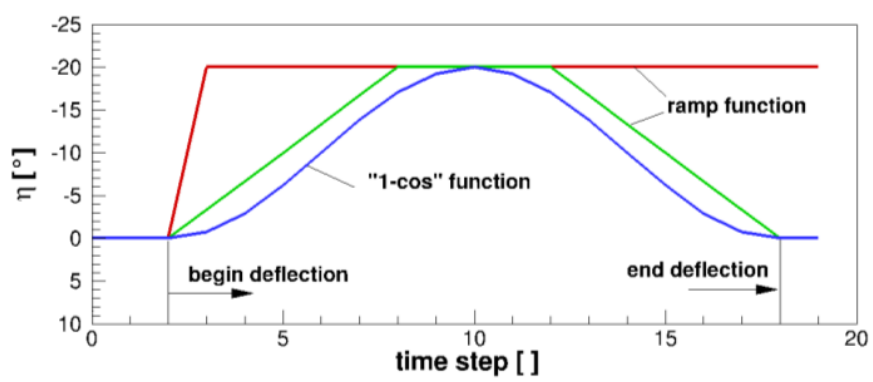

Figure 19: Predefined time histories of symmetrical aileron deflections investigated

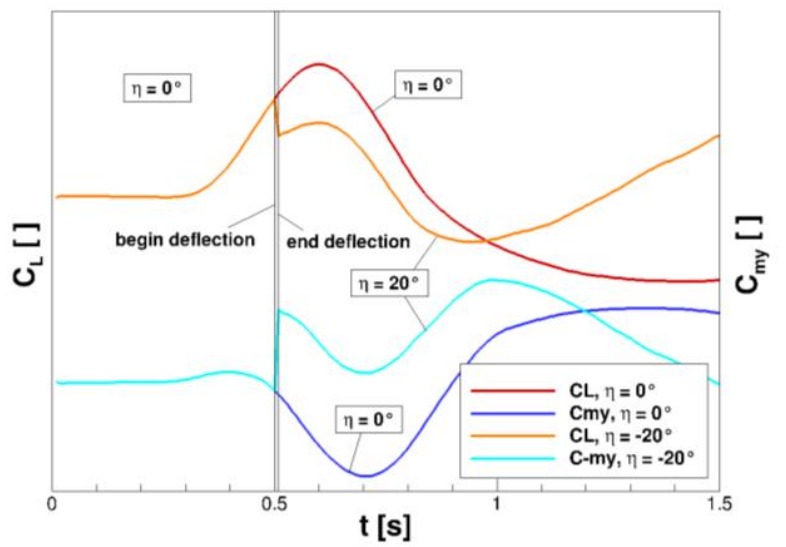

Figure 20: Effect of aileron deflections according to ramp function (see Fig.19 red) on transient lift and pitching moment during gust encounter

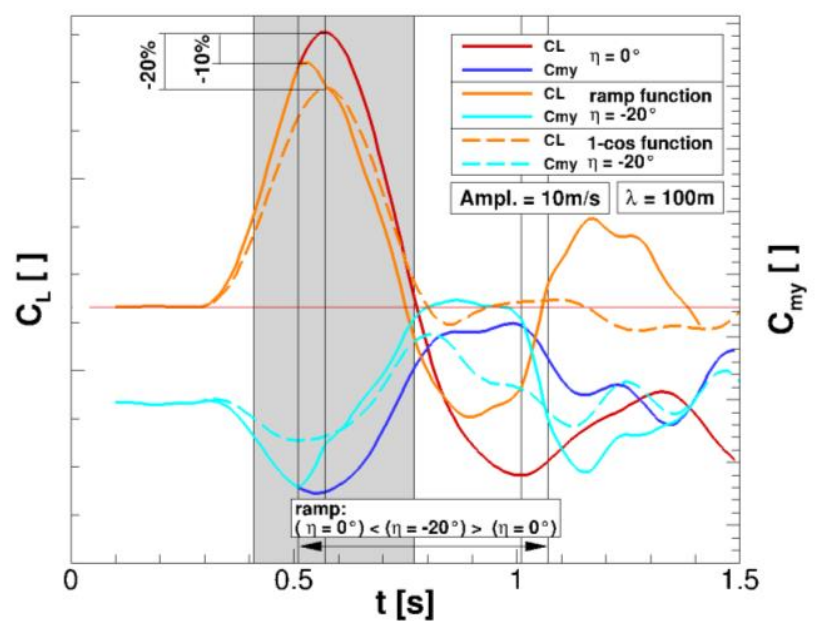

Figure 22: Comparison of lift and pitching moment curves of a configuration without and with different aileron deflections 
If the aileron is extended at a lower speed and retracted at a later instant of time (compare Fig 19 (green)), two results for the time-dependent lift coefficients using ramp functions with different start time are shown in Fig. 21. In both cases the aileron is extended from $\eta=0^{\circ}$ to $\eta=-20^{\circ}$ within $\Delta \mathrm{t}=0.06 \mathrm{~s}$, then keep the deflection constant at $\eta=-20^{\circ}$ and is retracted again within $\Delta \mathrm{t}=0.06 \mathrm{~s}$. The differences are the beginning and the end of the deflection period. In the first case it starts at $t=0.27 \mathrm{~s}$ and end at $\mathrm{t}=0.77 \mathrm{~s}$ (green). The reduction of the lift coefficient due to the negative deflection can be seen obviously, but in comparison with the non-deflected result the influence of the entire gust leads to a similar maximum lift coefficient. An alleviation of the lift coefficient is obtained in the second case. The aileron deflection period is between $0.51 \mathrm{~s}<\mathrm{t}<1.07 \mathrm{~s}$ (orange). Before the maximum lift is reached at $\mathrm{t}=0.57 \mathrm{~s}$ (non-deflected case) the aileron deflection started. The maximum and minimum aerodynamic responses are reduced, especially in the lift characteristic of $-10 \%$ (see Fig 22). However, the deflection of the aileron, with a "1-cosine"-function with the same aileron angle of $\eta=-20^{\circ}$, leads to a $20 \%$ reduced lift increase. In this case the deflection of the aileron is directly coupled with the beginning of the aerodynamic lift response. Even after the maximum vertical gust speed has left the fuselage rear end downstream, the disturbances in the lift and in the pitching moment behavior are smaller. However, the aero-structure coupled reactions are not negligible.
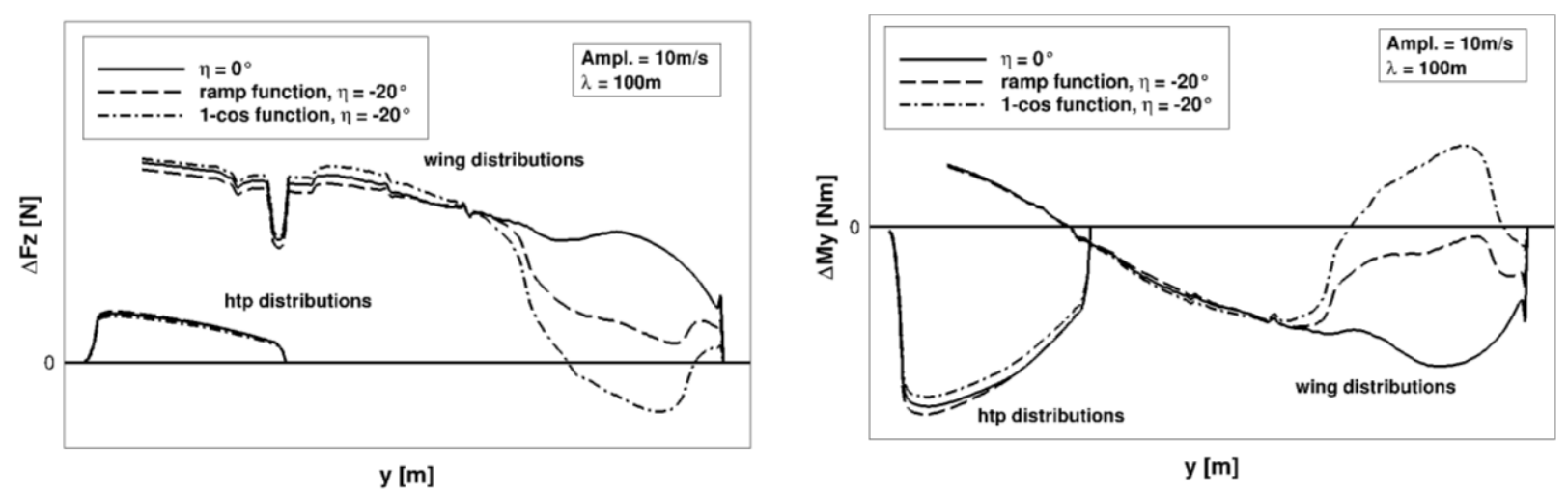

Figure 23: Span-wise distributions of maximum aerodynamic delta z-force (left) and y-moment (right) on wing and HTP for different aileron deflection functions during gust encounter

Fig. 23 shows the associated distributions over wing and HTP span of maximum $\Delta \mathrm{Fz}$ force and $\Delta \mathrm{My}$ moment during gust encounter. The results for control surface deflections according to ramp function and '1-cosine'-function are compared to the reference solution without aileron deflection (the clean configuration). The main load reduction effect on the wing, as expected, is confined to the area close to the deflected aileron; minor influences are visible on inboard wing and HTP. The outcome of the analysis is: the '1-cosine' function reduces aerodynamic loads the most significantly---at least far better than ramp function, even though the maximum aileron deflections are in both cases the same.

\section{Summary and Outlook}

For unsteady gust encounter simulations, a multidisciplinary process chain is used, which takes the aerodynamic (CFD), structural-dynamic (CSM) and flight mechanic (6DOF) characteristics of an aircraft into account.

Sensitivity studies, including the influences of the gust amplitude and gust wavelength, as well as the influence of vertical and lateral gust series, are presented and analyzed relating to the aerodynamic behavior of the overall aircraft configuration. With the parameter settings examined here, the resulting, time-dependent force and moment coefficients of the entire configuration as well as span-wise load distributions on the wing and on the horizontal tail plane are discussed. Here, the dependence between the gust excitation frequency and the structural / aerodynamic model response deserves special mention.

Basic examinations have been carried out with a reference configuration without load reduction measures. The ability to include control elements in the model description is used for further investigations to determine the possible load reduction of the respective integrated elements. Within these simulations different functions for the aileron deflections were investigated and the results were compared with those of the configuration without aileron 
deflections in order to determine the influence on the resulting forces and moments as well as the load distributions of the wing and the horizontal tail plane.

It can be shown in one case, that a load reduction of $20 \%$ is achieved, using the "1-cosine" function for the aileron deflection. Further investigations have to be done, in order to understand the interactions between the influence of the gust onto the aerodynamic behavior of the aircraft and the time-dependent controlled reaction of the aileron deflections using a flight control system in an updated process chain.

Furthermore, additional control surfaces (elevator, rudder, spoiler) have to be taken into account in the gust encounter simulations, to get a better understanding of the coupled aerodynamic, structural and flight mechanic behavior and their respective potential contribution to the gust load alleviation.

\section{Acknowledgments}

The process chain applied here for multidisciplinary simulations of gust encounter scenarios was developed in the scope of DLR project Digital-X [2]. The authors would like to thank Markus Ritter of the DLR Institute of Aeroelasticity, for his leading role in the development of the process chain and his continuous support on its use.

\section{References}

${ }^{1}$ Xu, J., and Kroo, I., "Aircraft Design with Active Load Alleviation and Natural Laminar Flow," Journal of Aircraft, Vol. 51, No. 5, 2014, pp. 1532, 1545. doi:10.2514/1.C032402.

${ }^{2}$ Reimer, L., Heinrich, R., Ritter, M.: Towards higher-precision maneuver and gust loads computations of aircraft: status of related features in the CFD-based multidisciplinary simulation environment FlowSimulator. Accepted for publication in: Dillmann, A. et al. (eds.): New Results in Numerical and Experimental Fluid Mechanics XII - Contributions to the 21th STAB/DGLR Symposium Darmstadt, Germany, Notes on Numerical Fluid Mechanics and Multidisciplinary Design, (2018).

${ }^{3}$ Kroll, N. et al.: DLR Project Digital-X: towards virtual aircraft design and flight testing based on highfidelity methods. CEAS Aeronaut. J., 7(1):3-27, (2016).

${ }^{4}$ Reimer, L. et al.: The FlowSimulator | A software framework for CFD-related multidisciplinary simulations. NAFEMS Conf.: Computational Fluid Dynamics (CFD) - Beyond the Solve, Munich, Germany, 2-3 Dec, (2015).

${ }^{5}$ Reimer, L. et al.: CFD-based Gust Load Analysis for a Free-flying Flexible Passenger Aircraft in Comparison to a DLM-based Approach. AIAA Aviation 2015, June 22-26, Dallas TX, USA (2015).

${ }^{6}$ Schwamborn, D., Gerhold, T., Heinrich, R.: The DLR TAU Code: Recent Applications in Research and Industry. In proceedings of European Conference on Computational Fluid Dynamics, ECCOMAS CDF 2006, Delft, The Netherland (2006).

${ }^{7}$ CENTAURSOFT, http://centaursoft.com.

${ }^{8}$ DLR TAU code, http://tau.dlr.de.

${ }^{9}$ Ritter, M.: Nonlinear Numerical Flight Dynamics of Flexible Aircraft in the Time Domain by Coupling of CFD, Flight Mechanics and Structural Mechanics, New Results in Numerical and Experimental Fluid Mechanics VIII, Springer-Verlag, Vol. 121, 2010, p339-347.

10 Heinrich, R., Michler, A.: Unsteady Simulation of the Encounter of a Transport Aircraft with a Generic Gust by CFD Flight Mechanics Coupling, CEAS, ID140, (2009).

11 Heinrich, R.: Simulation of Interaction of Aircraft and Gust Using the TAU-Code, in Dillmann, A. et al.: New Results in Numerical and Experimental Fluid Mechanics IX, Notes on Numerical Fluid Mechanics and Multidisciplinary Design, Springer-Verlag, Vol. 124, pp. 503-511 (2014).

12 Heinrich, R., Reimer, L.: Comparison of different approaches for gust modeling in the CFD Code TAU, International Forum on Aeroelasticity and Structural Dynamics, 24-27June, Bristol, UK (2013). 